\title{
From the patients' perspective: what it is like to suffer from eating disorders
}

\author{
Giovanni Stanghellini ${ }^{1,2} \cdot{\text { Giovanni Abbate } \text { Daga }^{3}[\text { Daldo Ricca }}^{4}$
}

Received: 18 April 2020 / Accepted: 29 April 2020 / Published online: 21 May 2020

(c) Springer Nature Switzerland AG 2020

\begin{abstract}
The available treatments of Eating Disorders (EDs) mirror an excessive focus on symptoms to be eliminated rather than on the acknowledgment of what is relevant from the patient's perspective. This Editorial offers a critical review of the limitations of the DSM-5-oriented approaches, as well as of their extreme consequences, namely ocularcentrism, nosographism, and paternalistic moralism. To overcome these limitations, it is suggested to get back to Psychopathology as the basic science of psychiatric practice whose aim is to grasp the distinctly personal dimension of the patient's experience and to connect understanding with care. With the help of Psychopathology, clinicians engaged in the treatment of ED patients will better make sense of what it is like to suffer from these disorders and be encouraged to suspend their judgment and take patient's perspective in the light of their troubled existence which is rich in meanings and not merely in abnormal beliefs and trivial anomalous behavior. According to these principles, treatment is a journey shared with the patient, which allows her/him to feel recognized and accepted in terms of her/his individuality.
\end{abstract}

Eating Disorders (EDs) are affected by the same epistemological morbus that pervades the whole field of psychiatry [1]. The main symptoms of these epidemics are ocularcentrism, nosographism, and a peculiar kind of moralism.

Ocularcentrism is the shift of focus from the patients' personal subjective experience to visible signs that is from the patients' complaints to their abnormal behavior. In the search for reliable evidence, the phenomena of lived experience are overlooked or externalized and transformed into observable diagnostic indexes. The clinicians' attention is mainly attracted by observable components, that is the ways patients eat or do not eat and the appearance of their bodies. This shift of focus becomes clear in both specific treatment

The article is part of the Topical Collection on Psychopathological models and Eating and Weight Disorders

Giovanni Stanghellini

giovanni.stanghellini@unich.it

1 Department of Psychological, Health and Territorial Sciences, G. D’Annunzio University, Chieti, Italy

2 D. Portales University, Santiago, Chile

3 Departement of Neuroscience, University of Turin, Turin, Italy

4 Psychiatry Unit, Department of Health Sciences, University of Florence, Florence, Italy settings and daily conversations whenever disease or healthrelated topics are brought up [2]. In this light, EDs tend to be represented as mere disorders of eating behavior and anatomical body. This third-person representation does not reflect the first-person experience of those who suffer from an ED. This epistemological weakness of ocularcentrism can concur with generating serious ethical conflicts between beliefs, emotions, and worldviews of the patients and their carers.

The second critical point related to ocularcentrism is summed up in the following question: should we continue to base our nosography on surface signs picked up for their reliability? Rather, should we try to develop novel ways to capture potentially more informative or deeper symptoms that might emerge from the careful phenomenological analysis [3]? This level of symptom assessment would certainly help to enlarge our understanding of morbid conditions like EDs. In contrast, an assessment approach focusing on a checkliststyle assembly of descriptive symptoms is quite far from good practice in psychiatry. About one century ago, dementia praecox was re-conceptualized as schizophrenia via a paradigm shift focusing on "split-brain" or "mind" as the primary disorder at the origin of "dementia" as its apparent epiphenomenon or outcome. Focusing on EDs as aberrant eating behaviors resembles believing that diabetes should be considered as a kidney_-rather than an endocrine—disease. 
This shift of focus from secondary to "core" phenomena, and from behavioral to experiential symptoms, may sound quite obvious, yet it is not fully achieved in our field. Feeding and Eating Disorders, as they are described in the DSM5 , are an excellent example of the supremacy of behavior symptoms over patients' beliefs, attitudes, emotions, and worries. Behavioral similarities of clinical conditions guide the creation of diagnostic categories, despite relevant psychopathological and clinical differences of the included disorders (e.g., PICA and anorexia nervosa [AN]). At a merely behavioral level, PICA and AN could be considered quite similar, as both share abnormal eating behaviors and impaired physical functioning. In contrast, muscle dysmorphia (reverse anorexia), although sharing with AN peculiar anomalies concerning one's own lived body experience, is classified elsewhere.

The third critical point related to ocularcentrism is the substantial disinterest in the implicit mind functioning. Ocularcentrism focuses on what is visible, thus minimizing the relevance of the invisible dimensions of the patients' subjectivity. In doing so, patients' unconscious, including psychodynamic, phenomenological, and cognitive dimensions, are overlooked, despite their relevance in achieving a full understanding of the psychopathological condition. In the patient-therapist dialog, we can learn things that cannot be known with an objectivating gaze.

Stemming from ocularcentrism, nosographism is the second serious epistemological weakness in the field of EDs. Nosographism can be defined as the obsession to establish clear-cut diagnoses based on objective, measurable signs. Visible signs are preferred to experiential symptoms because of their supposed higher reliability. The search for reliable diagnostic indexes is not a problem itself, but it may become a serious shortcoming when affecting the main goals of the clinical interview. In particular, if the only purpose is to establish a diagnosis rather than holistically understanding the patient's condition, the clinician may not be able to grasp "what it is like" to have a given experience and making sense of it. For instance, the symptom "loss of control over eating", which characterizes a large part of ED sufferers, if considered as a stand-alone entity, seems to be a unique marker shared by different diagnoses. Loss of control overeating is mainly driven by anger and aggressiveness in bulimic patients, and by mood depression in patients suffering from binge eating disorder, thus involving different psychopathological cores and therapeutic implications [4].

This approach follows a rigid pattern of questions oriented by operationalized criteria aiming at achieving a nosographic diagnosis. This may entail so-called "procrustean errors" (i.e., stretching and trimming the patient's symptomatology to fit criteria [5]), and "tunnel vision" (i.e., avoiding the assessment of those phenomena which are not included in standard interviews since unrelated to diagnostic criteria
[6]). Tunnel vision may entail the perpetuation of systematic inattention to all those features that are not included in mainstream diagnostic schemas, potentially impeding the evolution of psychopathological knowledge [7]. It should be borne in mind that diagnostic criteria represent mere conventions whose purpose is to allow carers to communicate with a shared language. They are conceptual entities, not real entities. As such, they may change over time following the development of science. For example, amenorrhea was discarded as a criterion for AN by the DSM task force [9] since its presence was not related to AN psychopathological severity [8].

Another negative consequence of nosographism is that many junior psychiatrists, trained to conceive diagnostic criteria as representing the whole patients' disordered condition, could consider operational criteria as "all you need to know" about that condition. Nosographism thus may pave the way to "psychiatry made easy" and to its impoverishment [10]. In this vein, the greatest risk is that such a simplified formulation of mental disorders may bring us back to reductionism and determinism.

A further downside of nosographism is nosographic pulverization, in which a myriad of different behavioral details is considered. As a result, a plethora of sub-syndromes is created, to the detriment of the psychopathological investigation, aiming instead to shed light on the experiential core underlying multiple epiphenomena. In the field of EDs, another weakness of the current diagnostic approaches (i.e., DSM-5 and ICD 11) is demonstrated by the diagnostic cross-over. A large part of ED patients shows diagnostic instability so that many individuals can meet overtime full criteria for different ED diagnoses. This suggests that some core ED features remain unresolved, eventually determining over the lifespan different symptoms in the same patient [11, 12]. Moreover, the criteria applied to measure the severity of AN (e.g., Body Mass Index), bulimia nervosa (number of inappropriate compensatory behaviors) and binge eating disorder (frequency of episodes of binge eating) do not predict course and outcome of these syndromes and do not provide reliable clinical information over the long-run. Therefore, it is not surprising that these severity criteria are only occasionally used in the literature [13-18].

Moralism is about judging rather than trying to understand others. Relevant evaluative elements are to be found in DSM Criterion (c) for AN (the relevant evaluative elements italicized): "disturbance in the way (she/he experiences her/ his) body weight or shape, undue influence of body weight or shape on self-evaluation, or persistent lack of recognition of the seriousness of (her/his) current low body weight". Persons with AN will, of course, evaluate these criteria very differently from their family and their therapists. Eating and body experiences have positive meanings for ED sufferers [19]. These opposite perspectives are a key challenge in the 
treatment of AN. Not surprisingly, a head-on therapeutic collision with the patient's values of AN-if handled as mere abnormal cognitions-will hamper treatment effectiveness [20]. Treatment may, of course, involve a range of measures including medical interventions, but any chance of effective intervention depends on engaging the disturbances underlying AN (with more detail, the way patients experience their body) in treatment [19, 21-26]. Even more so if we focus on patients' behavior (e.g., fasting) and their motivating value (e.g., drive for thinness).

To avoid moralistic judgments about the beliefs and behavior of people with AN, it is of the utmost importance to acknowledge that the "negative values" defining their presenting problems (e.g., starvation) is underpinned by and reflect a deeper underlying set of values mainly triggered by their disturbed experience of their body. There will be no possibility to change their point of view, since, given their subjective experience of reality about fatness, thinness, food, and starvation, they are just right [27]. Therapy does not consist of establishing what is morally or cognitively right or wrong according to common-sense; therapists should rather make a sense-searching journey together with their patients suffering from an ED without prepackaged answers. In the value-system of people with $\mathrm{AN}$, food has not merely an aesthetic value but rather an ethical value: it is a sin and a temptation. Fatness has a moral value pointing at laziness, lack of self-care, and self-control. Thinness is more valuable than anything else, including health [28]. Strict rules are needed to do no wrong and to be led astray, while starvation is the unique salvation practice [7].

Instead of tackling patients' presenting symptoms, the aim of therapy should be to help them make sense of their drive for thinness and starvation by connecting them with a core psychopathological anomaly: their difficulties in feeling their own body and in sustaining a stable sense of themselves as embodied agents.

Valuing the value of recognition is the starting point for developing an idea of care based on value-acknowledgment and value-pluralism. Our patients' values depart from common-sense and from medical values as they are embedded in life-worlds that are different from each other and our own. In mental disorders, there is an axiological dimension, a component of human suffering that has been long disregarded by clinical psychiatry [29]. The neglect of the value system of people suffering from mental disorders contributes to seeing them merely as people who bear pathological experiences and beliefs. This may have not only a stigmatizing effect but may also contribute to judge some of these people's actions as meaningless and incomprehensible.

To avoid these risks is exactly the task of Psychopathology: to acknowledge what is relevant from the patient's perspective-how one's vulnerability and suffering are distinctly personal-and to establish an effective dialog between patient's and clinician's perspectives. Psychiatry is about establishing such a dialog in the context of care for troubled human existence [30]. Psychopathology connects understanding with care, and endeavors to establish an epistemological as well as an ethical framework for this.

We believe that these points are not taken for granted in the treatment of ED patients. Treating symptoms is fundamental and necessary in severe conditions like EDs; however, ignoring the different psychopathological roots from whom eating symptoms derive and by which are nourished is also an obvious and potentially nefarious mistake. The essence of Psychopathology as the basic science in psychiatry [31] is to grasp patients' specific perspective through the prism of their own lived experiences.

After all, science does not need only evidence and demonstrations, but also conceptual frameworks and theoretical models stimulating research and debate on phenomena. Not everything real is also visible, and not all knowledge is evidence-based knowledge: although this may seem a hazard, theories may help to provide an overarching and more complete explanation of what ED's are and to achieve not only treatment but also comprehensive care.

We need evidence, but we also need theories to make sense of empirical data. Our discipline is grounded not only on evidence but also on theoretical hypotheses and models, including those provided by psychoanalysis, cognitivism, and phenomenology. This topical collection aims to stimulate scholars and researchers to submit to this journal articles focused on the link between empirical observations and not merely ocular centric, nosography-based and moralistic perspectives on ED's.

For this purpose, we encourage the submission of papers that, building on a solid theoretical basis, are aimed at the investigation of the experiential and unconscious dimensions of the human condition of those suffering from ED's. Qualitative research and patients' first-person contributions are welcome. Particular attention will be paid to those papers analyzing body- and treatment-related problems in patients with egosyntonic values potentially putting their life at risk. Researches on different psychopathological trajectories leading to the development of eating symptoms, as well as data or analyses on so-called "comorbidity" between EDs and other syndromes, will also be considered if discussed within a psychopathology framework.

We hope that this collection will help to improve the opportunities for scientific exchange, paving the way to contexts of care focused on patients' personal views rather than on check-list symptoms.

Funding No funding. 


\section{Compliance with ethical standards}

Conflict of interest The authors declare that they have no conflict of interest.

Ethical approval This article does not contain any studies with human participants or animals performed by any of the authors.

Informed consent For this type of study, formal consent is not required.

\section{References}

1. Gardner C, Kleinman A (2019) Medicine and the mind-The consequences of psychiatry's identity crisis. N Engl J Med 381(18):1697-1699. https://doi.org/10.1056/NEJMp1910603

2. Mooij A (2012) Psychiatry as a human science: phenomenological, hermeneutical and lacanian perspectives. In: Mooij A (ed) Contemporary psychoanalytic studies. Brill Rodopi, Leiden

3. Kendler KS (2008) Why does psychiatry need philosophy. introduction. In: Kendler KS, Parnas J (eds) Philosophical issues in psychiatry. Explanation, phenomenology, and nosology. The Johns Hopkins University Press, Baltimore, pp 7-8

4. Castellini G, Mannucci E, Lo Sauro C, Benni L, Lazzeretti L, Ravaldi C, Rotella CM, Faravelli C, Ricca V (2011) Different moderators of cognitive-behavioral therapy on subjective and objective binge eating in bulimia nervosa and binge eating disorder: a three-year follow-up study. Psychother Psychosom 81:1120. https://doi.org/10.1159/000329358

5. McGuffin P, Farmer A (2001) Polydiagnostic approaches to measuring and classifying psychopathology. Am J Med Genet (Neuropsychiatr Genet) 105:39-41. https://doi.org/10.1002/10968628(20010108)105:1\%3c39:aid-ajmg1054\%3e3.3.co;2-k

6. Van Praag HM, Asnis GM, Kahn RS, Brown SL, Korn M, Friedman JMH, Wetzler S (1990) Nosological tunnel vision in biological psychiatry: a plea for a functional psychopathology. Ann NY Acad Sci. https://doi.org/10.1111/j.1749-6632.1990.tb16905.x

7. Stanghellini G, Mancini M (2017) The therapeutic interview. Emotions, values, and the life-world. Cambridge University Press, Cambridge

8. Abbate Daga G, Campisi S, Marzola E, Rocca G, Peris C, Campagnoli C, Peloso A, Vesco S, Rigardetto R, Fassino S (2012) Amenorrhea in eating disorders: Poor stability of symptom after a one-year treatment. Eat Weight Disord 17(2):e78-e85. https:// doi.org/10.3275/7962

9. American Psychiatric Association (2013) Diagnostic and statistical manual of mental disorders. Am J Psychiatry. https://doi. org/10.1176/appi.books.9780890425596.744053

10. Kendler KS (2015) Introduction to "Psychiatry made easy: operation(al)ism and some of its consequences.". In: Kendler KS, Parnas J (eds) Philosophical issues in psychiatry III: the nature and sources of historical change. Oxford University Press, Oxford

11. Castellini G, Lo Sauro C, Mannucci E, Ravaldi C, Rotella CM, Faravelli C, Ricca V (2011) Diagnostic crossover and outcome predictors in eating disorders according to DSM-IV and DSM-V proposed criteria: A 6-year follow-up study. Psychosom Med 73(3):270-279. https://doi.org/10.1097/PSY.0b013e31820a1838

12. Milos GF, Baur V, Muehlebach S, Spindler A (2013) Axis-I comorbidity is linked to prospective instability of diagnoses within eating disorders. BMC Psychiatry 13(1):295. https://doi. org/10.1186/1471-244X-13-295

13. Bardone-Cone AM, Harney MB, Maldonado CR, Lawson MA, Robinson DP, Smith R, Tosh A (2010) Defining recovery from an eating disorder: conceptualization, validation, and examination of psychosocial functioning and psychiatric comorbidity. Behav Res Ther 48(3):194-202. https://doi. org/10.1016/j.brat.2009.11.001

14. Castellini G, Montanelli L, Faravelli C, Ricca V (2014) Eating disorder outpatients who do not respond to cognitive behavioral therapy: a follow-up study. Psychother Psychosom 83(2):125-127. https://doi.org/10.1159/000356496

15. Castellini G, Lelli L, Cassioli E, Ciampi E, Zamponi F, Campone B, Monteleone AM, Ricca V (2018) Different outcomes, psychopathological features, and comorbidities in patients with eating disorders reporting childhood abuse: A 3-year follow-up study. European Eating Disorders Review 26(3):217-229. https://doi. org/10.1002/erv.2586

16. Castellini G, Lelli L, Corsi E, Campone B, Ciampi E, Fishe AD, Mallardo L, Monteleone AM, Rotella F, Tofani T, Vignozzi L, Zamponi F, Maggi M, Ricca V (2017) Role of sexuality in the outcome of anorexia nervosa and bulimia nervosa: a 3-year follow-up study. Psychother Psychosom 86(6):376-378. https://doi. org/10.1159/000477176

17. Fichter MM, Quadflieg N (2016) Mortality in eating disorders Results of a large prospective clinical longitudinal study. Int J Eat Disord 49(4):391-401. https://doi.org/10.1002/eat.22501

18. Linardon J, de la Piedad GX, Brennan L (2017) Predictors, moderators, and mediators of treatment outcome following manualised cognitive-behavioural therapy for eating disorders: a systematic review. European Eating Disorders Review 25(1):3-12. https:// doi.org/10.1002/erv.2492

19. Marzola E, Panepinto C, Delsedime N, Amianto F, Fassino S, Abbate-Daga G (2016) A factor analysis of the meanings of anorexia nervosa: intrapsychic, relational, and avoidant dimensions and their clinical correlates. BMC Psychiatry 16:190. https://doi. org/10.1186/s12888-016-0894-6

20. Fulford KWM, Stanghellini G (2019) Values and values-based practice. In: Stanghellini G (ed) The Oxford handbook of phenomenological psychopathology. Oxford University Press, Oxford, pp 354-366. https://doi.org/10.1093/oxfordhb/9780198803 157.001 .0001

21. Abbate-Daga G, Amianto F, Delsedime N, De-Bacco C, Fassino S (2014) Correction: resistance to treatment and change in anorexia nervosa: a clinical overview. BMC Psychiatry 13:294. https://doi. org/10.1186/1471-244X-14-62

22. Fassino S, Abbate-Daga G (2013) Resistance to treatment in eating disorders: a critical challenge. BMC Psychiatry 13:282. https ://doi.org/10.1186/1471-244X-13-282

23. Stanghellini G, Castellini G, Brogna P, Faravelli C, Ricca V (2012) Identity and eating disorders (IDEA): a questionnaire evaluating identity and embodiment in eating disorder patients. Psychopathology 45(3):147-158. https://doi.org/10.1159/00033 0258

24. Stanghellini G, Trisolini F, Castellini G, Ambrosini A, Faravelli C, Ricca V (2015) Is feeling extraneous from one's own body a core vulnerability feature in eating disorders? Psychopathology 48(1):18-24. https://doi.org/10.1159/000364882

25. Castellini G, Stanghellini G, Godini L, Lucchese M, Trisolini F, Ricca V (2015) Abnormal bodily experiences mediate the relationship between impulsivity and binge eating in overweight subjects seeking bariatric surgery. Psychother Psychosom 84(2):124126. https://doi.org/10.1159/000365765

26. Cascino G, Castellini G, Stanghellini G, Ricca V, Cassioli E, Ruzzi V, Monteleone P, Monteleone AM (2019) The role of the embodiment disturbance in the anorexia nervosa psychopathology: a network analysis study. Brain Sci. https://doi.org/10.3390/ brainsci9100276

27. Monteleone AM, Castellini G, Volpe U, Ricca V, Lelli L, Monteleone P, Maj M (2018) Neuroendocrinology and brain imaging of reward in eating disorders: a possible key to the treatment 
of anorexia nervosa and bulimia nervosa. Prog Neuro-Psychoph 80(Pt B):132-142. https://doi.org/10.1016/j.pnpbp.2017.02.020

28. Charland LC, Hope T, Stewart A, Tan J (2013) Anorexia nervosa as a passion. Philos Psychiatry Psychol 20(4):353-365. https:// doi.org/10.1353/ppp.2013.0049

29. Sadler JZ (2005) Values and psychiatric diagnosis, vol 2. Oxford University Press, Oxford

30. Marzola E, Albini E, Delsedime N, Fassino S, Abbate-Daga G (2019) Therapeutic alliance in inpatients with severe anorexia nervosa. Eur Eat Disord Rev 27(6):671-681. https://doi.org/10.1002/ erv. 2687
31. Stanghellini G, Broome MR (2014) Psychopathology as the basic science of psychiatry. Br J Psychiatry 205(3):169-170. https://doi. org/10.1192/bjp.bp.113.138974

Publisher's Note Springer Nature remains neutral with regard to jurisdictional claims in published maps and institutional affiliations. 